\title{
Baseline Laboratory Profile of HIV Positive Patients on Antiretroviral Therapy in Jos North Central Nigeria: Implications for Prevention, Treatment, Care and Support
}

\author{
Christian Ogoegbunem Isichei1,2*, Mercy Wakili Isichei2,3, Jean Emile Njab4, \\ Johnson Ibidun Rotimi2, Tinuade Abimbola Oyebode ${ }^{5,6}$, Charles Ujunwa Anyaka 2,5, \\ Kenneth Emeka Enwerem², Ayuba Ishiaku Affi', Lucius Chidiebere Imoh', \\ Alexander Ogielu Abu' ${ }^{1}$, Solomon Abiola Asorose', Noel Omuya Amadu', \\ Propser Ihenacho Okonkwo', Ngozi Ijeoma Okoro ${ }^{4}$
}

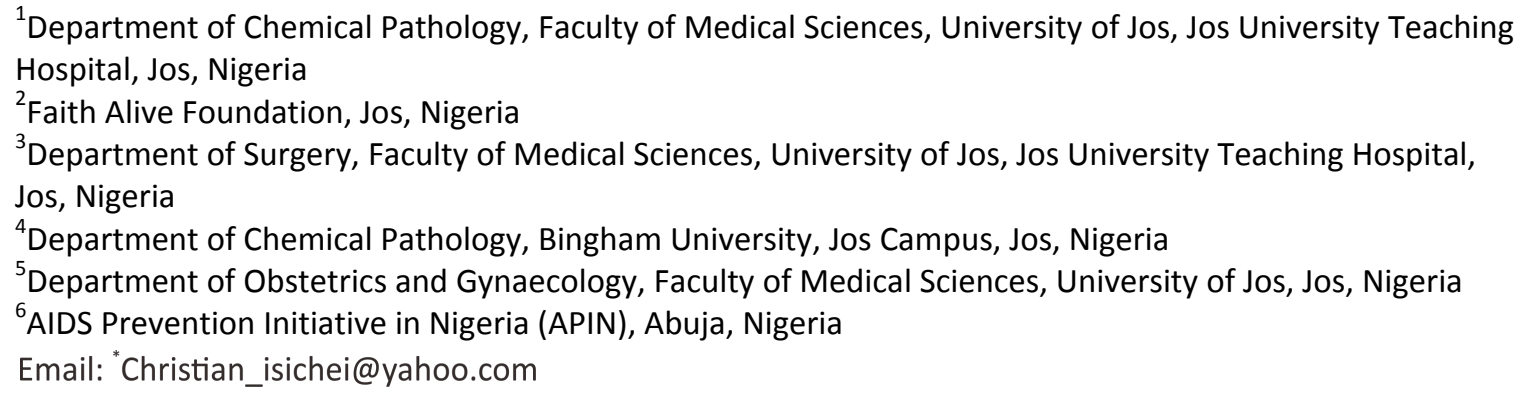

Received 23 November 2015; accepted 28 December 2015; published 31 December 2015

Copyright (C) 2015 by authors and Scientific Research Publishing Inc.

This work is licensed under the Creative Commons Attribution International License (CC BY). http://creativecommons.org/licenses/by/4.0/

(c) (i) 0 pen Access

\section{Abstract}

Background: We characterized baseline laboratory data of patients to identify priority treatment areas, most affected populations, anticipated clinical complications and assessed the potential burden of retention in care in Jos, Plateau State-North Central Nigeria. Methods: This study was a cross-sectional design from January 2004 to December 2005 at Faith Alive Foundation (FAF). All participants were HIV-positive and underwent pre-antiretroviral therapy counseling based on the national antiretroviral therapy (ART) guidelines and baseline laboratory testing. Data were captured on Microsoft Excel, validated on Epi Info and analyzed on SPSS version 21 at $P<.05$ level of significance. Results: Total of 1499 (463 men and 1036 women) participants were evaluated in this study. The age and sex related distribution of participants showed that majority $(80.3 \%$ for males and $92.5 \%$ for females) were 16 - 45 years old. Amylase and creatinine were significantly

\footnotetext{
${ }^{*}$ Corresponding author.

How to cite this paper: Isichei, C.O., Isichei, M.W., Njab, J.E., Rotimi, J.I., Oyebode, T.A., Anyaka, C.U., Enwerem, K.E., Affi, A.I., Imoh, L.C., Abu, A.O., Asorose, S.A., Amadu, N.O., Okonkwo, P.I. and Okoro, N.I. (2015) Baseline Laboratory Profile of HIV Positive Patients on Antiretroviral Therapy in Jos North Central Nigeria: Implications for Prevention, Treatment, Care and Support. World Journal of AIDS, 5, 328-334. http://dx.doi.org/10.4236/wja.2015.54036
} 
higher in males than females $(P=.02)$. Anaemia was the most common baseline abnormality $(63 \%$ for females and $58 \%$ for males), while baseline CD4 count was significantly lower in males than females $(P<.02)$ and at one-third had elevated liver enzymes (AST and ALT). Conclusion: The baseline laboratory profile of most HIV positive patients in Jos and environs of North Central-Nigeria was characterized by anaemia, elevated creatinine, and abnormal liver transaminase levels (AST and ALT). This pre-ART laboratory result suggests that HIV-positive individuals have multiple clinical abnormalities which may require more extensive care than just treating the HIV disease.

Keywords

Baseline Laboratory Profile, HIV-Positive Patients, PEPFAR, HTC, Nigeria

\section{Introduction}

At a time when the world is beginning to project the "end of the AIDS epidemic" by 2030, 71\% of the global HIV burden estimated at 24.7 million (23.5 - 26.1 million) people is still in sub-Sahara Africa [1]. Furthermore, about $81 \%$ of HIV infection is reported in ten countries of Ethiopia, Mozambique, Kenya, Uganda, Malawi, Tanzania, Zimbabwe, Zambia, Nigeria and South Africa. More than 50\% of HIV infections are found in South Africa and Nigeria alone [2] [3]. In all these countries the epidemic has affected all socio-economic strata, dehumanized millions, impoverished communities, increased the vulnerabilities of women and children, reversed developmental gains and reduced life expectancy [4].

Nigeria is confronted with a mixed epidemic, driven by low personal risk perception, multiple and concurrent sexual partnership, ineffective and inefficient medical services for sexually transmitted infections, entrenched gender inequalities and inequities, chronic and debilitating poverty, as well as extensive HIV/AIDS stigma and discrimination [5]. Although HIV prevalence has stabilized from 3.6\% to 3.4\% in Nigeria within a two-year period according to the 2-yearly sentinel surveys, about 220,394 new infections occurred in 2013; less than 10\% adults know their HIV status; approximately 3.2 million people live with the virus; and less than $50 \%$ of eligible individuals are on antiretroviral therapy [6].

In 2001 a pilot study was introduced by the Nigerian government for ART that targeted only 10,000 Nigerians adults with some gaps in its implementation. The support of the United States President's Emergency Plan for AIDS Relief (PEPFAR) from 2004 and other development partners since 2009 have dramatically changed the quality of life of millions living with HIV in Nigeria. The number of HIV testing and counseling (HTC) sites increased from 1074 to 7075; the number of individuals who received HTC within the same period also grew from 1.7 million to 4.1 million. The number of sites providing ART also increased from 393 to 820 within the same period [5].

In spite of the progress made so far, Nigeria's HIV programmes rely on financial donors. The current global economic crisis resulted in dwindling financial resources threatening the ability to sustain HIV Prevention, Treatment, Care and Support programmes. In order to compensate, current programmes will require data-driven allocations of funds. Baseline laboratory data of patients appear most appropriate to identify priority treatment areas and most affected populations, anticipate clinical complications and assess the potential burden of retention in care [7] [8]. This study was designed to characterize the baseline laboratory profile of HIV-positive patients in order to assess their clinical burden before Treatment (ART), Care and Support in Jos, Plateau StateNorth Central Nigeria.

\section{Methods}

This study was a cross-sectional design that was implemented from January 2004 to December 2005 at Faith Alive Foundation and Prevention of Mother To Transmission (PMTCT) of HIV Center in Jos, Plateau state, North Central, Nigeria. Faith Alive Foundation (FAF) was established in 1996. FAF and PMTCT Center became the first faith based organization to receive the PEPFAR grant in Nigeria in 2004 under AIDSRELIEF/ University of Maryland, Baltimore, USA. Trained Birth Attendants became essential part of its HIV pro- 
grammes in 2004 [9]. In 2004, PEPFAR was supervised by 5 groups in Africa with the Harvard group (now APIN) as well as AIDSRELIEF being in Nigeria. Ethical approval was obtained from the ethics committee of FAF, Plateau Specialist Hospital, Jos and the Health Department of Jos North Local government area.

\subsection{Study Participants}

Participants were recruited by simple random sampling technique from outpatients who tested positive during the provider initiated HIV testing and counselling (HTC) according to the national HTC algorithm at FAF from January 2004 to December 2005. We had envisaged a sample size of 1250 participants for a study precision of $1 \%$ at 95 confidence interval with a prevalence of HIV infection of 7\%. 1499 consented (documented consent in the client intake form) to participate in the study. All participants underwent pre-ART counseling in line with the national ART guidelines and referred to the laboratory for baseline profile.

\subsection{Laboratory Analysis}

Ten milliliters of whole blood was collected from each eligible participant between 8am and 9am with five milliliters each in a plain universal bottle and in an EDTA bottle. Sysmex Haematology Autoanalyser was used to measure haemoglobin and other parameters as full blood count analysis, Partec Cyflow was used to measure CD4-T Lymphocytes count, and Refloctron Chemistry Analyzer was used to measure amylase, alanine aminotransferase (ALT), aspartate aminotransferase (AST) and creatinine. All samples were analyzed according to PEPFAR/WHO laboratory programme Standard Operating Procedures (SOP) in single series and run analysis. Adequate quality control measures were used including use of controls, standards and duplication of samples within runs.

\subsection{Data Management}

All data were captured on Microsoft excel, validated on Epi Info. and analyzed on SPSS version 21 at $\mathrm{P}<.05$. Descriptive statistics (frequency distribution, means and standard deviation) were calculated. Z-score was used to compare means, Fisher exact and odd ratios were used to compare gender-based differences on proportion of abnormal baseline laboratory test at $\mathrm{P}<5 \%$ significance.

\section{Results}

A total of 1499 participated in this study with a median age of 31 years and the sex related distribution of participants showed that majority [80.3\% for males (463) and 92.5\% for females (1036)] were 16 - 45 years old (Table 1). Females were more than twice affected than males (69.1\% versus $30.9 \%$ respectively).

Baseline laboratory tests indicated that amylase, creatinine were significantly higher in males than females (P $=.02)$. Baseline haemoglobin was significantly lower in females than males $(\mathrm{P}<.01)$, while baseline CD4 count was significantly lower in males than females $(\mathrm{P}<.02)$. Baseline liver enzymes did not significantly vary by gender (Table 2 and Table 3).

\section{Discussion}

This study was designed to characterize the baseline laboratory profile of HIV positive patients before antiretroviral therapy in order to assess the clinical burden on Prevention, Treatment, Care and Support in Plateau StateNorth Central Nigeria. Our findings showed that majorities (>80\%) were 16 - 45 years old and more women en-

Table 1. Age and sex distribution of participants.

\begin{tabular}{cccc}
\hline Age groups (years) & Male $(\mathrm{n}=463) \mathrm{N}(\%)$ & Female $(\mathrm{n}=1036) \mathrm{N}(\%)$ & Total N (\%) \\
\hline $0-15$ & $28(6.0)$ & $17(1.6)$ & $45(0.03)$ \\
$16-30$ & $65(14.0)$ & $472(45.6)$ & $536(35.8)$ \\
$31-45$ & $307(66.3)$ & $486(46.9)$ & $793(52.9)$ \\
$>45$ & $63(13.6)$ & $61(5.8)$ & $124(0.08)$ \\
\hline
\end{tabular}


Table 2. Mean differences of baseline laboratory tests by gender.

\begin{tabular}{ccccc}
\hline Laboratory Tests & Male $(\mathrm{n}=463)$ & Female $(\mathrm{n}=1036)$ & z-Score & P-value \\
\hline Amylase (U/L) & $148.4 \pm 103.8$ & $135.1 \pm 99.0$ & 2.34 & $.02^{*}$ \\
AST (U/L) & $28.6 \pm 16.5$ & $23.3 \pm 12.7$ & 1.42 & .16 \\
ALT (U/L) & $20.3 \pm 10.0$ & $16.2 \pm 10.2$ & 1.85 & .06 \\
Creatinine (mg/dl) & $1.1 \pm 0.7$ & $0.8 \pm 0.5$ & 6.52 & $.001^{*}$ \\
Haemoglobin (g/dl) & $12.3 \pm 4.9$ & $11.5 \pm 7.2$ & 2.56 & $.01^{*}$ \\
CD4 count (cells/ $\mu \mathrm{l})$ & $168.8 \pm 140.5$ & $189.4 \pm 184.4$ & 2.38 & $.02^{*}$ \\
\hline
\end{tabular}

Table 3. Distribution of baseline laboratory abnormalities by gender.

\begin{tabular}{|c|c|c|c|c|c|}
\hline Laboratory Abnormalities & Total N (\%) & Males N (\%) & Females N (\%) & OR & P-value \\
\hline Elevated Amylase & $783(52)$ & $255(55)$ & $528(51)$ & $1.1(0.63-1.93)$ & .70 \\
\hline Elevated Creatinine & $625(42)$ & $273(59)$ & 352 (34) & $2.8(1.57-4.96)$ & $<.01^{*}$ \\
\hline Anaemia $^{* *}$ & $922(62)$ & 269 (58) & $653(63)$ & $0.8(0.45-1.43)$ & .50 \\
\hline Depleted CD4 Count & 437 (29) & 199 (43) & $238(23)$ & $2.5(1.37-4.65)$ & $<.01^{*}$ \\
\hline Elevated ALT & $518(35)$ & $176(38)$ & 342 (33) & $1.2(0.69-2.22)$ & .50 \\
\hline Elevated AST & 509 (34) & $167(36)$ & 342 (33) & $1.1(0.63-2.04)$ & .70 \\
\hline
\end{tabular}

${ }^{*} \mathrm{P}<.05 .{ }^{* *}$ Heamoglobin less than 10 milligrams per deciliter.

rolled for Treatment, Care, Support and Prevention than men (69.1\% versus 30.9\% respectively) and up to 84\% of young (16 - 30 years) patients were women This profile is similar to recent HIV/AIDS reproductive and health survey (NARHS plus) conducted in Nigeria, as well as several other studies performed across the continent [9]-[11]. National HIV/AIDS and Reproductive Health Survey-Plus 2012 (NARHS plus 2012) reported, about four-fifths (83\%) of the female respondents compared with $78 \%$ of the males accessed HIV prevention services with the age interval of 15 - 40 years [9], while Nwokedi et al. [10], and Derbe et al. [11], observed 93\% and $91 \%$ of participants within the age bracket of 20 - 49 years respectively.

Our data revealed that while elevated creatinine and CD4 depletion were the most significant $(\mathrm{P}<.01)$ baseline abnormalities ( $\mathrm{OR}=2.8$ and $\mathrm{OR}=2.5$, respectively), anaemia was the most common baseline abnormality (63\% for females and 58\% for males) and may be nutritional in origin as per morphological picture. However further studies are needed to classify the various forms of anaemia Gender based differences in laboratory testing were more significant for men, except for anemia which may be due to reproductive issues.. These observations were consistent with Kamga et al. [12], and Agbaji et al. [13], who identified creatinine as a predictor of impaired Glomerular Filtration Rate (GFR) among HIV positive patients in Douala, Cameroon and Jos-Plateau in Nigeria. Also, a cross-sectional community based study in Nepal [14] found that the prevalence of anemia was associated with $44.8 \%, 49.3 \%, 60.3 \%$ and $69.6 \%$, first to fourth quartile, of HIV symptom burden respectively, suggesting that anemia was a strong co-morbidity among HIV patients.

Takuva et al. [15] in South Africa suggested that sustained low haemoglobin was an adverse prognostic marker for patients on Zidovudine. It is also pertinent to note that Nigeria Integrated National Guidelines for HIV Prevention, Treatment and Care (2014) has removed Zidovudine as first line treatment for PMTCT in other to prevent anaemia and hepatotoxicity. Baseline anaemia therefore has implications for use of Zidovudine especially in countries with limited choice of regimens. Prompt identification of anaemia will possibly improve morbidity and mortality of patients initiating ART.

Similarly, Assefa et al. [16] reported a $42.9 \%$ prevalence of anaemia with a strong correlation between the prevalence of anemia and age in a retrospective cohort study in Ethiopia.

Our data indicated that approximately 34\% of patients had elevated liver enzymes (38\% and 36\% for both ALT and AST respectively among men, 33\% for both ALT and AST among women) (see Table 3). This sug- 
gests the potential to develop a wide spectrum of hepatic pathologies including liver decompensation, hepatocellular cancer especially among those affected [17]-[19]. This will worsen in patients on Nevirapine or to be placed on Nevirapine in countries with limited choice regimens. HIV is also known to infect multiple cells in the liver, leading to enhanced intrahepatic apoptosis, activation and fibrosis [20]. Finally, HIV can also alter gastro-intestinal tract permeability, leading to increased levels of circulating lipopolysaccharide that may have an impact on liver function [21] [22].

From the foregoing, abnormal laboratory baseline parameters identified in this study that may translate into routine implication for treatment are 34\% liver related abnormalities and about $62 \%$ anaemia. In sub-Sahara Africa in general and Nigeria in particular, where individuals have very poor health seeking behaviours, reversing the tide of pre-ART clinical burden will remain a challenge for a long time. Despite efforts to make health insurance scheme accessible and affordable, most communities, towns, and villages fail to have any form of health insurance available. The passage of the national health bill is encouraging but has not yet been well implemented especially the development of a minimum health package for all Nigerians through a Primary Health Care Development Agency. The recent decision to suspend free financial support for baseline laboratory tests, namely chemistry and hematology in all PEPFAR funded facilities is likely to complicate the identification of other diseases in HIV-infected individuals. Until African governments take responsibility for providing universal healthcare for their populations, the clinical burden of pre-ART patients will continue to compromise the prognosis of many people living with HIV and the 90-90-90 HIV plan a mirage (Test and Identify 90\%, Treat 90\% (on ART) and ensure 90\% suppressed as per viral load results).

\section{Limitations of Study}

This study had some limitations. Firstly, the cross sectional design did not allowed us to establish a gender balance ratio at recruitment. Consequently, females were more likely to be recruited than males, because some came for antenatal care, also they are more open than men and tend to ignore the stigma associated with HIV/AIDS disease in their quest for Prevention, Treatment, Care, and Support unlike men. Secondly, patients were not triaged by HIV/AIDS disease progression and for this reason poor health seeking behaviour may have predisposed some patients to compromised baseline data. Thirdly, we recognized that it is ambitious to draw population level conclusions to treatment burden based on programme data only, because programme data have limited socio-dynamic factors that impact on treatment burden like access, quality of care and cost of care. Finally, our design did not provide prediction outcomes of treatment burden based on baseline data for future intervention and even though past years of work, findings very relevant in current settings.

\section{Conclusion}

The baseline laboratory profile of HIV positive patients evaluated in this study in Jos, Plateau State, North Central-Nigeria was characterized by anaemia, elevated creatinine and abnormalities of liver enzyme levels and recent studies suggest that this is still so if not worse with fast declining global economy and increasing poverty worldwide due to a number of factors including strives and crisis of various dimensions. About one in two was anaemic or had elevated creatinine and about one in three had abnormal liver transaminase levels. This pre-ART laboratory profile is a clinical burden with the potential to compromise the prognosis of many persons living with the virus in Plateau state.

\section{Recommendations}

African countries and governments should take responsibility for the health of their populations by implementing policies that promote and support health seeking behaviours that will reduce the clinical burden of pre-ART patients in order to improve the prognosis of many persons living with the virus in Plateau state.

\section{Note}

First presented as_- "Using Baseline Laboratory profiles to inform programmes: Lessons from Faith Alive Foundation, Jos, Nigeria”. Book of Abstracts p. 46-47, APIN Scientific Conference, Abuja 22-23, October 2013 (Theme; Integrating Research into service delivery; the gains, challenges and opportunities). 


\section{References}

[1] Global Report (2014) UNAIDS Report on Global AIDS Epidemic, 4.

[2] UNAIDS (2014) Beginning the End of the AIDS Epidemic. The GAP Report, 262-4.

[3] Dixon, S., McDonald, S. and Roberts, J. (2002) The Impact of HIV and AIDS on Africa’s Economic Development. BMJ, 324, 232-234. http://dx.doi.org/10.1136/bmj.324.7331.232

[4] Federal Republic of Nigeria (2014) Global AIDS Response Country Progress Report (GARPR).

[5] Federal Ministry of Health [Nigeria] (2013) National HIV \& AIDS and Reproductive Health Survey, 2012 (NARHS Plus). Federal Ministry of Health Abuja, Nigeria, 10.

[6] Fasakin, K.A., Omisakin, C.T., Esan, A.J., Adebara, I.O., Owoseni, I.S., Omoniyi, D.P., Ajayi, O.D., Ogundare, R.G. and Moronkeji, M.B. (2014) Total and CD4+ T-Lymphocyte Count Correlation in Newly Diagnosed HIV Patients in Resource-Limited Setting. Journal of Medical Laboratory and Diagnosis, 5, 22-28.

[7] World Health Organization (2006) Patient Monitoring Guidelines for HIV Care and Antiretroviral Therapy. World Health Organization, Geneva.

[8] Isichei, C.O. and Ammann, A.J. (2015) The Role of Trained Birth Attendants in Delivering PMTCT Services. American Journal of Health Research, 3, 232-238.

[9] Federal Ministry of Health [Nigeria] (2013) National HIV \& AIDS and Reproductive Health Survey, 2012 (NARHS Plus). Federal Ministry of Health Abuja, Nigeria, 276-277.

[10] Nwokedi, E.E., Ochicha, O., Mohammed, A.Z. and Saddiq, M.N. (2007) Baseline CD4 Lymphocyte Count among HIV Patients in Kano, Norther Nigeria. African Journal of Health Sciences, 14, 3-4.

[11] Derbe, M., Monga, D.P. and Daka, D. (2013) Immunological Response among HIV/AIDS Patients before and after ART Therapy at Zewuditu Hospital Addis Ababa, Ethiopia. American Journal of Research Communication, 1, 104-115.

[12] Kamga, H.L.F., Assob, J.C.N., Njunda, A.L., Nde Fon, P., Nsagha, D.S., Atanga, M.B.S., Weledji, P., Puinta, D.P. and Achidi, E.A. (2011) The Kidney Function Trends in Human Immunodeficiency Virus/Acquired Immune Deficiency Syndrome (HIV/AIDS) Patients at the Nylon District Hospital, Douala, Cameroon. Journal of AIDS and HIV Research, 3, 30-37.

[13] Agbaji, O.O., Onu, A., Agbaji, P.E., Muazu, M.A., Falang, K.D. and Idoko, J.A. (2011) Predictors of Impaired Renal Function among HIV Infected Patients Commencing ART in Jos-Nigeria. Nigeria Medical Journal, 52, 182-185. http://dx.doi.org/10.4103/0300-1652.86133

[14] Martin, C., Poudel-Tandukar, K. and Poudel, K.C. (2014) HIV Symptom Burden and Anemia among HIV Positive Individuals: Cross-Sectional Results of a Community Based Positive Living with HIV (POLH) Study in Nepal. PLoS ONE, 9, e116263.

[15] Takuva, S., Maskew, M., Brennan, A.T., Sanne, I., MacPhail, A.P. and Fox, M.P. (2013) Anemia among HIV-Infected Patients Initiating Antiretroviral Therapy in South Africa: Improvement in Hemoglobin Regardless of Degree of Immunosuppression and the Initiating ART Regimen. Journal of Tropical Medicine, 2013, Article ID: 162950.

[16] Assefa, M., Abegaz, W.E., Shewamane, A., Medhin, G. and Belay, M. (2015) Prevalence and Correlates of Anemia among HIV Infected Patients on ART at Zewditu Memorial Hospital, Ethiopia. BMC Hematology, 15, 6.

[17] Zhang, Y.X., Gui, X.E., Zhong, Y.H., Rong, Y.P. and Yan, Y.J. (2011) Cancer in Cohort of HIV-Infected Population: Prevalence and Clinical Characteristics. Journal of Cancer Research and Clinical Oncology, 137, 609-614. http://dx.doi.org/10.1007/s00432-010-0911-y

[18] Panos, G., Farouk, L., Stebbing, J., Holmes, P., Valero, S., Randell, P., Bower, M., Gazzard, B., Anderson, M. and Nelson, M. (2009) Cryptogenic Pseudo Cirrhosis: A New Clinical Syndrome of Non-Cirrhotic Portal Hypertension (Unassociated with Advanced Fibrosis) That Can Be Detected by Transient Elastography in Patients with HIV. Journal of Acquired Immune Deficiency Syndromes, 52, 525-527. http://dx.doi.org/10.1097/QAI.0b013e3181bb27b1

[19] Crum-Cianflone, N., Dilay, A., Collins, G., Asher, D., Campin, R., Medina, S., Goodman, Z., Parker, R., Lifson, A., Capozza, T., Bavaro, M., Hale, B. and Hames, C. (2009) Nonalcoholic Fatty Liver Disease among HIV-Infected Persons. Journal of Acquired Immune Deficiency Syndromes, 50, 464-473. http://dx.doi.org/10.1097/QAI.0b013e318198a88a

[20] Chang, P.E., Miquel, R., Blanco, J.L., Laguno, M., Bruguera, M., Abraldes, J.G., Bosch, J. and Garcia-Pagan, J.C. (2009) Idiopathic Portal Hypertension in Patients with HIV Infection Treated with Highly Active Antiretroviral Therapy. American Journal of Gastroenterology, 104, 1707-1714. http://dx.doi.org/10.1038/ajg.2009.165

[21] Crane, M., Iser, D. and Lewin, S.R. (2012) Human Immunodeficiency Virus Infection and the Liver. World Journal of Hepatology, 4, 91-98. http://dx.doi.org/10.4254/wjh.v4.i3.91 
[22] Steffan, A.M., Lafon, M.E., Gendrault, J.L., Schweitzer, C., Royer, C., Jaeck, D., Arnaud, J.P., Schmitt, M.P., Aubertin, A.M. and Kirn, A. (1992) Primary Cultures of Endothelial Cells from the Human Liver Sinusoid Are Permissive for Human Immunodeficiency Virus Type 1. Proceedings of the National Academy of Sciences USA, 89, 1582-1586. http://dx.doi.org/10.1073/pnas.89.5.1582 